\title{
Factors Influencing Children's Full Immunization in Ethiopia
}

\author{
Eshetu Gurmu ${ }^{1}$ and Dula Etana ${ }^{2}$ \\ Centre for Population Studies, Addis Ababa University, Ethiopia
}

\begin{abstract}
Child morbidity and mortality in Ethiopia is mainly due to vaccine preventable diseases. Although numerous interventions have been made since the 1980's to increase vaccination coverage, the level of full immunization is low in the country. This study examines factors influencing children's full immunization based on data on 1927 children aged 12-23 months extracted from the 20I I Ethiopian Demographic and Health Survey. Multinomial logistic regression model was fitted to identify predictors of full immunization. The result shows that only $24.3 \%$ of the children were fully immunized. There was significant difference between regions in immunization coverage in which Tigray, Dire Dawa, and Addis Ababa performed well. In Oromia, Afar, Somali, Benishangul-Gumuz, and Gambela regions, the likelihood of children's full immunization was significantly lower. Children born to mothers living in households with better socio-economic status, with frequent access to media, and who visit health facilities for antenatal care were more likely to be fully immunized. The results imply the importance of narrowing regional differences, improving women's socio-economic status and utilization of antenatal care services, and strengthening culture-sensitive media campaign as a means of achieving full immunization of all children.
\end{abstract}

Key words: Children, Immunization, Region, Ethiopia

\section{Résumé}

La morbiditéet la mortalité infantileen Ethiopieest principalement due auxmaladies évitables par vaccination. Bien que de nombreusesinterventionsont été faitesdepuis les années 1980pour augmenterla couverture vaccinale, le niveau dela vaccination complèteest faibledans le pays. Cette étude examine les facteurs qui influencent la vaccination complète des enfants, basée sur les données sur I 927 enfants âgés de 12 à 23 mois extraites de l'Enquête démographique et de santé 201 I éthiopienne. Modèle de régression logistique multinomiale a été équipé d'identifier les prédicteurs de la vaccination complète. Le résultat montre que seulement $24,3 \%$ des enfants étaient complètement vaccinés. II y avait de différence significative entre les régions de la couverture vaccinale dans lequel Tigray, Dire Dawa et Addis-Abeba ont bien performé. Dans Oromia, Afar, Somali, BenishangulGumuz, et les régions de Gambela, la probabilité de la vaccination complète des enfants était significativement plus faible. Les enfants nés de mères de meilleur statut socio-économique, avec un accès fréquent aux médias, et qui visitent les établissements de santé pour les soins prénatals étaient plus susceptibles d'être complètement vaccinés. Les résultats impliquent l'importance de réduire les disparités régionales, améliorer le statut socio-économique et l'utilisation des femmes des services de soins prénatals, et le renforcement de la culture sensible campagne médiatique comme un moyen de parvenir à la vaccination complète de tous les enfants.

Mots clés : Enfants, la vaccination, région, l'Ethiopie

${ }^{1}$ Corresponding author - email address - eshetugurmu@gmail.com

2Email address - etanad29@gmail.com 


\section{Introduction}

Immunization is a cost effective method of preventing child morbidity and mortality (Odusanya et al. 2008). Immunization not only enhances child survival via prevention of debilitating illness and disability but also transforms the lives of children by giving them the chance to grow up healthy (Rutherford et al. 2009). Furthermore, full immunization has positive effect on economic development by reducing costs of health care (Tadesse et al. 2009; UNICEF 2013). There are, however, many children who are not yet reached through immunization services. More than $70 \%$ of the unimmunized or partially immunized children live in 10 developing countries including Ethiopia (WHO and UNICEF 2013) with significant inequalities in child immunization within and between countries (UNICEF 20I3). Sub-Saharan Africa (SSA) documented the lowest coverage of all vaccination types compared with other regions (UNICEF and WHO 20I2).

Death during the first few years of life in Ethiopia is among the highest in the world. In $201 \mathrm{I}$, infant and under-five mortality rates were 59 and 88 per 1,000 live births, respectively (Central Statistical Agency and ICF International 20I2). Although the figure is less than the level in the preceding years, it is still high, demanding concerted efforts to achieve the health targets of the country. According to the Ethiopian Ministry of Health (2010a), about 427,000 under five children die each year. Child morbidity and mortality in the country occurs mainly due to vaccine preventable diseases such as pneumonia, malaria, diarrhoea, measles and neonatal causes (Ministry of Health 20I0b; Etana and Deressa 20I2).

Extended Program on Immunization (EPI) that emphasized 6 vaccines had started in Ethiopia in 1980 (Kidane et al. 2008). The Government of Ethiopia has made numerous interventions that have yielded notable progresses in increasing vaccination coverage (Ministry of Health, 20I I; Central Statistical Agency and ICF International 20I2). However, with lowest level of full immunization in SSA, the country's EPI target is not yet achieved as none of the vaccine type reached $90 \%$ coverage in $201 \mathrm{l}$. Community based surveys conducted in different parts of the country also found low level of full immunization (for instance, 22.9\% in Eastern Ethiopia (Mohammed and Atomsa 2013); $27.7 \%$ in Central Ethiopia (Etana and Deressa 20I2); $41.7 \%$ in South Ethiopia (Tadesse et al. 2009); and $51 \%$ in North Ethiopia (Kidane and Tekie 2003)). Given the prevailing situation, achieving full immunization in Ethiopia will be a challenge with heavy consequence of increasing the risk of contracting diseases such as diphtheria, Haemophilus influenza type B, hepatitis B, measles, tetanus, pertussis, poliomyelitis, and yellow fever (WHO 20I0). Achieving the goal also requires evidencebased concerted efforts.

There are several studies on child immunization in Ethiopia. Most of the studies mainly focused on specific localities (Kidane and Tekie 2003; Tadesse et al. 2009; Etana and Deressa 2012; Mohammed and Atomsa 2013). Despite concerted efforts for more than three decades, there is disparity in the successes achieved in different parts of the country. However, there is lack of empirical evidence on the variation in the attainment of the target of EPI across geographical settings. This study, therefore, examines regional variation in the coverage of children's full immunization on the one hand and demographic and socio-economic features that predict immunization status of children on the other. The study is believed to provide further insight on the problem so that proper actions would be taken to enhance the health wellbeing of children through full coverage of immunization.

\section{Correlates of children's full immunization: literature review}

The health seeking behaviour of parents for their children constitutes an important component of children's healthy development (Bbaale 20I3). Specifically, full immunization of children depends on the awareness of parents about the benefits and schedule of vaccination, and their commitment to adhere to the schedules. Parental decision of getting their children fully immunized is a function of the supply and demand side health factors (Waters et al. 2004).

In developing countries, the use of health services is partly dependent on the nature of service provision that incorporates accessibility and quality of immunization services. Geographical accessibility (i.e. distance and travelling time) influences the decision of parents not only to get their children vaccinated but also to complete the entire package (Wagstaff et al. 2004). For instance, studies conducted in India (Ghei et al. 2010), Ethiopia (Kidane et al. 2008), and Bangladesh (Rahman and Obaida-Nasrin, 20I0) found that proximity to a health facility significantly increased the likelihood of children's full immunization. Some studies showed that children in rural areas were less likely to be fully immunized (Fadnes et al. 20II). Contrarily, other studies conducted in Ethiopia (Kidane and Tekie 2003), India (Dixit et al. 20/3), and Gambia (Payne et al. 20/3) found better immunization coverage in rural areas. Apart from geographical accessibility, availability of human and material resources, quality of service providing institutions (e.g. working hours, waiting 
time, etc.), timeliness of providing immunization services, and supervisory visits by health workers play crucial roles in influencing health seeking behaviour of parents and level of full immunization (Bishai et al. 2002; Wagstaff et al. 2004; Waters et al. 2004).

The demand for and utilization of immunization services are influenced by various demographic and socio-economic characteristics of households and mothers (Ghei et al. 2010; Fadeyi 2013). Son preference, sib size, and birth order are among demographic factors associated with the likelihood of being fully immunized (Bronte-Tinkew and Dejong 2005; Ghei et al. 2010). While males were more likely to be fully immunized than girls in India (Munshi and Lee 2000; Rahman and Obaida-Nasrin 2010; Afzal and Zainab 20l2), no systematic difference between males and females was observed in studies conducted in Jamaica and Trinidad and Tobago (Bronte-Tinkew and Dejong 2005) and Ethiopia (Kidane et al. 2008).

Mothers with greater parity were less likely to fully immunize their children in Bangladesh (Rahman and Obaida-Nasrin 2010), Jamaica as well as Trinidad and Tobago (Bronte-Tinkew and Dejong 2005), and South Africa (Fadnes et al. 20l I). While some studies show lower likelihood of full immunization among lower order births (Afzal and Zainab 20I2), others found higher likelihood of full immunization among later born children (Bronte-Tinkewand Dejong 2005). The negative effects of sib size and birth order on full immunization are often associated with competition for resources.

Mothers' responsibility for children's full immunization is affected, among other things, by their level of education, access to media, utilization of maternal health care services, and economic status. Children born to educated mothers were more likely to be fully vaccinated than children whose mothers had no/lower level of education in Cameroon (Waters et al. 2004), Niger and Nigeria (Gage et al. 1997; Odusanya et al. 2008), Uganda (Babirye et al. 20II; Bbaale 20I3), India (Munshi and Lee 2000; Ghei et al. 2010), and Bangladesh (Afzal and Zainab 2012). Children born to mothers with professional occupation were most likely to be fully immunized in Uganda (Bbaale 20I3). Contrary to this, children of working mothers were less likely to be fully immunized in India (Ghei et al. 20l0).

Media is one of the means through which utilization of immunization services can be enhanced (Rahman and Obaida-Nasrin 20I0; Mukungwa, 20I5). In Bangladesh (Afzal and Zainab 20I2) and Uganda (Bbaale 2013), parents' exposure to mass media significantly improved immunization coverage. Antenatal care (ANC) visit was associated with children's full immunization in Nigeria (Fadeyi 20/3),
India (Dixit et al. 20I3), and Bangladesh (Rahman and Obaida-Nasrin 2010). In addition, the likelihood of children's full immunization was significantly higher for mothers who delivered in health facilities (Fadnes et al. 20II; Etana and Deressa 20I2; Fadeyi 20I3; Mukungwa, 2015).

In Niger and Nigeria (Gage et al. 1997) and India (Pande and Yazbeck 2002), increase in income resulted in higher chances of children's full immunization. Similar results were documented in other studies (Bronte-Tinkew and Dejong 2005; Tadesse et al. 2009; Ghei et al. 2010; Rahman and Obaida-Nasrin 2010; Afzal and Zainab 20I2). On the other hand, there is evidence that economic factor was not significantly associated with immunization coverage (Payne et al. 20l3).

The review of previous studies generally indicates that parental, household, and institutional factors are important in explaining variation in the status of children's full immunization. However, the empirical results show contrasting effects of most of the variables on children's full immunization. Thus, this study investigates the influence of these factors on children's full immunization in Ethiopia where the services are provided in diverse demographic, socioeconomic, and geographical settings.

\section{Data and methods}

This study was based on the Ethiopian Demographic and Health Survey (EDHS) that was conducted in $201 \mathrm{I}$ using nationally representative sample. Information on vaccination and related issues were collected on the women's questionnaire for all children under the age of 5 . The analysis was restricted to children 12-23 months old representing the youngest cohort of children who have reached the age by which they should be fully vaccinated (Central Statistical Agency and ICF International 20I2).

This study dealt with the 8 antigens (BCG, three doses of DPT, three doses of OPV and measles) that have been provided to children under the age of I through routine immunization service since 2007. The immunization status of children, i.e. the dependent variable, was categorized as (a) fully immunized if the child had received all of the 8 antigens; (b) partially immunized if the child received at least I but not all vaccines; and (c) not immunized if the child had not received any of the vaccines. A total of 1927 cases were included in the descriptive analysis (Table I). However, in the multivariate analysis, 278 cases with at least one variable missing the information were excluded. The independent variables included in the model were region of residence, child characteristics (sex and birth order), 
mother's characteristics (age group, educational level, marital status, religion, work status, access to media, number of antenatal care visit, and place of delivery), father's characteristics (father's education and occupation) and household characteristics (household wealth status). A composite index was created to measure wealth status. Possession of animals, agricultural land size, table, chair, use of kerosene pressure lamp, and roof material were considered to create the index for rural households whilst use of electricity, telephone, refrigerator, type of toilet facility and floor materials were used for those living in urban areas. Principal components analysis was employed to compute weights to create the index. It was then classified into low, medium, and high taking the first, second, and third triciles, respectively. Pregnant women are recommended to visit health facilities for ANC at least four times (WHO 2002) and this number was used to categorize the ANC variable.

Multinomial logistic regression model was fitted to identify variables predicting immunization status of children. It was preferred to others as the dependent variable was classified into three and logit ordered regression was not used as it deals with sequential order for which the categories of children's immunization status is not appropriate. Results of the multivariate analysis were reported in adjusted odds ratios. In addition, qualitative data were collected from Health Extension Workers (HEWs) and relevant experts from health bureaus through interviews from four regions (Tigray, Afar, Amhara, and Oromia). Qualitative data were transcribed and thematically analysed to supplement the statistical results.

Being mainly based on secondary data, this study has its own limitations. Firstly, as the EDHS is conducted to assess the basic demographic and health situation of the country, the data do not provide an opportunity to assess the effects of some of the underlying factors constituting the supply side effects. Secondly, it does not generate information on the quality of health and education services on immunization. Hence, some of these explanations are incorporated in this analysis indirectly based on qualitative data collected from health workers.

\section{Results}

\section{Differentials of children's immunization status}

Among children aged 12-23 months, only about onefourth $(24.3 \%)$ were fully immunized (Table I). Nearly three-fifth $(60.7 \%)$ was partially immunized, indicating that they have started the vaccination but dropped at some point without getting all the vaccines. Besides, $15 \%$ of the children were not vaccinated at all. The serious problem in Ethiopia is thus not only reaching a child but getting him/her the full dose of vaccination. Had it been possible to provide full immunization for each and every child that has taken at least one of the vaccines during its infancy, the immunization coverage would have reached over $80 \%$ in most of the regions (Table I Panels III and IV).

The coverage of immunization varies by background characteristics. Full immunization was higher in urban areas (42.4\%) than in rural areas (20\%). Among all regional states and city administrations, full immunization coverage exceeded $50 \%$ only in Tigray, Addis Ababa, and Dire Dawa. Lowest immunization coverage was observed in Afar, Oromia, Somali, and Gambela regions where only less than one-fifth of the children were fully immunized (Table I Panel IV). The percentage of fully immunized children consistently increased with increase in mother's educational level, in which $57.4 \%$ of children born to mothers with secondary and above level of education were fully immunized. Similarly, $45.5 \%$ of children whose fathers had secondary and above level of education were fully immunized. The level of full immunization was relatively higher $(30.8 \%)$ among children born to mothers in marital union than those whose mothers were not in union (23.9\%).

Although there were similarities in the level of full immunization between children born to mothers who were not working and those working in family businesses, over one-fourth (28\%) of children born to employed mothers were fully immunized. About $41 \%$ of children born to mothers with frequent access to media were fully immunized. Whilst only $15 \%$ of the children whose mothers hadn't visited ANC received full immunization, nearly half $(49 \%)$ of children whose mothers visited health facilities for ANC more than four times were fully immunized. Among mothers who delivered at health facility, 50\% of their children were fully immunized compared to only $20 \%$ of full immunization for children whose mothers delivered at home.

Only $17 \%$ of children from Muslim parents were fully immunized compared to $21 \%$ and $33 \%$ of children whose mothers follow Protestant and Orthodox religions, respectively. The percentage of children who were not vaccinated at all or partially vaccinated was higher among children whose mothers had no education, live in rural areas, higher birth order, no/limited access to media, no ANC visit, delivered at home, and from economically poor households(Table I Panel II). Full immunization coverage was one-third among those living in rich households. 
Table I: Distribution of immunization status of children age I2-23 months in Ethiopia by background characteristics, 20I I

\begin{tabular}{|c|c|c|c|c|c|c|c|c|c|}
\hline \multirow{3}{*}{ Variables } & \multirow{3}{*}{ Classifications } & \multirow[b]{2}{*}{ Number } & \multicolumn{3}{|c|}{ Immunization Status } & \multicolumn{4}{|c|}{ Vaccination } \\
\hline & & & $\begin{array}{l}\text { Unvac- } \\
\text { cinated }\end{array}$ & $\begin{array}{l}\text { Partially } \\
\text { immunized }\end{array}$ & $\begin{array}{c}\text { Fully } \\
\text { immunized }\end{array}$ & BCG & DPT3 & Polio3 & Measles \\
\hline & & I & II & III & IV & V & VI & VII & VIII \\
\hline \multirow{3}{*}{$\begin{array}{l}\text { Place of } \\
\text { residence }\end{array}$} & Rural & 1577 & 16.0 & 63.6 & 20.4 & 63.8 & 32.9 & 41.4 & 51.8 \\
\hline & Other urban & 269 & 10.0 & 47.6 & 42.4 & 78.8 & 57.0 & 64.1 & 77.1 \\
\hline & Addis Ababa & 81 & 2.3 & 18.6 & 79.1 & 97.7 & 88.4 & 81.4 & 93.0 \\
\hline \multirow{11}{*}{$\begin{array}{l}\text { Region of } \\
\text { residence }\end{array}$} & Tigray & 203 & 1.6 & 39.5 & 58.9 & 96.1 & 74.4 & 76.6 & 83.7 \\
\hline & Afar & 174 & 44.4 & 44.4 & 11.1 & 38.9 & 11.1 & 22.2 & 29.4 \\
\hline & Amhara & 222 & 11.2 & 62.6 & 26.2 & 67.7 & 39.5 & 48.3 & 61.9 \\
\hline & Oromia & 290 & 19.7 & 64.7 & 15.5 & 57.3 & 27.1 & 36.4 & 45.9 \\
\hline & Somali & 150 & 36.0 & 48.0 & 16.0 & 45.1 & 25.5 & 29.4 & 39.2 \\
\hline & BenishangulGumuz & 170 & 13.6 & 63.6 & 22.7 & 69.6 & 43.5 & 45.5 & 68.2 \\
\hline & SNNP & 253 & 11.3 & 64.5 & 24.2 & 73.4 & 38.5 & 47.3 & 57.8 \\
\hline & Gambella & $15 \mid$ & 12.5 & 75.0 & 12.5 & 75.0 & 25.0 & 42.9 & 50.0 \\
\hline & Harari & 115 & 0.0 & 60.0 & 40.0 & 80.0 & 60.0 & 60.0 & 60.0 \\
\hline & Addis Ababa & 81 & 2.3 & 18.6 & 79.1 & 97.7 & 88.4 & 81.4 & 93.0 \\
\hline & Dire Dawa & 118 & 0.0 & 42.9 & 57.1 & 85.7 & 71.4 & 83.3 & 83.3 \\
\hline \multirow{2}{*}{ Sex of child } & Male & 983 & 14.8 & 62.1 & 23.1 & 64.4 & 35.0 & 42.9 & 55.7 \\
\hline & Female & 944 & 15.1 & 59.2 & 25.7 & 68.5 & 39.3 & 47.4 & 55.8 \\
\hline \multirow{3}{*}{ Birth Order } & First & 364 & 12.9 & 57.0 & 30.1 & 29.0 & 41.1 & 47.6 & 61.0 \\
\hline & $2-4$ & 867 & 14.3 & 61.5 & 24.2 & 66.2 & 37.0 & 45.5 & 54.7 \\
\hline & $5+$ & 696 & 16.7 & 61.6 & 21.6 & 64.0 & 35.1 & 43.2 & 54.3 \\
\hline \multirow{3}{*}{$\begin{array}{l}\text { Mother's } \\
\text { age group }\end{array}$} & $15-24$ & 825 & 14.2 & 61.4 & 24.4 & 67.8 & 35.0 & 43.2 & 52.9 \\
\hline & $25-34$ & 860 & 16.4 & 59.1 & 24.5 & 65.3 & 40.1 & 47.9 & 58.8 \\
\hline & $35-49$ & 242 & 12.2 & 64.6 & 23.2 & 64.8 & 32.8 & 40.9 & 53.4 \\
\hline \multirow{3}{*}{$\begin{array}{l}\text { Mother's } \\
\text { education }\end{array}$} & No education & 1293 & 18.6 & 61.3 & 20.1 & 60.1 & 31.7 & 40.7 & 49.9 \\
\hline & Primary & 512 & 8.7 & 62.9 & 28.5 & 75.4 & 43.5 & 50.0 & 63.8 \\
\hline & Secondary and above & 122 & 0.0 & 42.6 & 57.4 & 100.0 & 72.5 & 75.5 & 89.2 \\
\hline \multirow{2}{*}{$\begin{array}{l}\text { Mother's } \\
\text { marital } \\
\text { status }\end{array}$} & Currently not in union & 1786 & 9.8 & 59.4 & 30.8 & 73.9 & 40.3 & 47.0 & 62.7 \\
\hline & Currently in union & $14 \mid$ & 15.3 & 60.8 & 23.9 & 65.8 & 36.8 & 44.9 & 55.2 \\
\hline \multirow{4}{*}{$\begin{array}{l}\text { Mother's } \\
\text { religion }\end{array}$} & Orthodox & 630 & 10.3 & 56.7 & 33.0 & 72.8 & 44.1 & 52.7 & 66.7 \\
\hline & Protestant & 363 & 18.2 & 60.8 & 21.0 & 65.2 & 38.3 & 47.0 & 49.3 \\
\hline & Muslim & 872 & 18.5 & 64.9 & 16.5 & 60.0 & 28.0 & 35.1 & 46.8 \\
\hline & Others & 34 & 7.5 & 70.0 & 22.5 & 62.5 & 35.0 & 50.0 & 65.0 \\
\hline \multirow{3}{*}{$\begin{array}{l}\text { Mother's } \\
\text { work status }\end{array}$} & Not working & 1021 & 16.5 & 61.0 & 22.5 & 63.2 & 34.1 & 40.7 & 52.1 \\
\hline & Working in family busines & 292 & 16.0 & 61.1 & 22.9 & 68.9 & 38.3 & 42.2 & 55.3 \\
\hline & Employed & 610 & 12.6 & 59.8 & 27.7 & 69.0 & 40.4 & 52.7 & 60.9 \\
\hline \multirow{3}{*}{$\begin{array}{l}\text { Mother's } \\
\text { access to } \\
\text { media }\end{array}$} & Not at all & 879 & 16.8 & 64.4 & 18.8 & 62.3 & 31.6 & 40.8 & 49.3 \\
\hline & Sometimes & 589 & 17.1 & 64.9 & 18.0 & 62.9 & 30.6 & 38.7 & 51.5 \\
\hline & Frequently & 459 & 9.4 & 49.3 & 41.3 & 77.3 & 54.2 & 60.0 & 71.6 \\
\hline \multirow{3}{*}{ ANC Visit } & No ANC & 991 & 21.6 & 63.8 & 14.6 & 53.1 & 24.3 & 45.0 & 57.3 \\
\hline & At least 4 times & 605 & 7.4 & 59.0 & 33.6 & 80.5 & 49.2 & 33.7 & 70.9 \\
\hline & More than 4 times & 246 & 0.0 & 51.4 & 48.6 & 93.4 & 70.1 & 72.8 & 85.9 \\
\hline \multirow{2}{*}{$\begin{array}{l}\text { Place of } \\
\text { delivery }\end{array}$} & Home & 1482 & 16.6 & 63.0 & 20.4 & 62.6 & 33.4 & 42.2 & 51.9 \\
\hline & Health facility & 326 & 4.8 & 45.2 & 50.0 & 88.4 & 64.7 & 64.7 & 83.5 \\
\hline & No Education & 949 & 16.8 & 62.3 & 20.9 & 60.1 & 34.6 & 40.8 & 51.8 \\
\hline Father's & Primary & 712 & 15.0 & 61.8 & 23.2 & 69.3 & 34.7 & 45.8 & 54.0 \\
\hline & Secondary and above & 235 & 5.7 & 48.9 & 45.5 & 85.8 & 58.5 & 63.6 & 82.4 \\
\hline Father's & Non-agricultural & 551 & 12.1 & 49.5 & 38.4 & 77.3 & 54.7 & 55.7 & 66.0 \\
\hline occupation & Agricultural & 1345 & 16.0 & 63.9 & 20.1 & 63.1 & 31.9 & 41.8 & 52.7 \\
\hline Household & Poor & 799 & 17.5 & 65.3 & 17.1 & 63.0 & 30.9 & 38.8 & 50.6 \\
\hline wealth & Medium & 535 & 12.5 & 62.6 & 24.9 & 67.6 & 37.4 & 47.8 & 58.4 \\
\hline status & Rich & 587 & 14.3 & 52.6 & 33.1 & 69.3 & 44.7 & 50.2 & 59.4 \\
\hline & Total & 1927 & 15.0 & 60.7 & 24.3 & 66.3 & 37.0 & 45.1 & 55.7 \\
\hline
\end{tabular}

Source: Computed by authors from the 20II EDHS data 
The percentage of children who received some of the vaccines (BCG, DPT3, Polio3, and Measles) is shown in Table I, Panels V-VIII. More than twothird of the children were vaccinated against BCG. However, less than half of the children received DPT3 and Polio3 vaccines with respective figures of $37 \%$ and $45 \%$. Since both of these vaccines are recommended to be given simultaneously, the difference between the two is due to campaignbased polio vaccination. The lowest level of DPT3 vaccination coverage indicates that it is very far from the long run plan of the Ministry of Health to achieve its coverage of $90 \%$ in all regions. The higher percentage of children vaccinated for BCG which is given at birth and the decline for the subsequent vaccines show that most children start vaccination but not follow the other doses that are given later. The percentage of children who received each of the vaccines was higher for urban residents, children born to well-educated parents, and children living in rich households.

\section{Multivariate results}

Results of the multivariate analysis showed wider regional variation in the level of immunization. Taking children in the Amhara region as a reference, those residing in Tigray region were respectively 3.18 and 8.38 times more likely to be fully vaccinated than those who are partially vaccinated and not. Better access to immunization opportunities were observed in Dire Dawa where the chances of full vaccination were about 5 and 4 times higher than those who were not immunized and partially immunized having taken those living in the Amhara region as a reference. Similarly, children living in Addis Ababa were 4.7 times more likely to be fully than partially immunized when compared to those living in Amhara region. Unlike this, chances of getting full as well as partial vaccination were slim among children living in Afar, Somali, Gambela, and Oromia regions. Worst of all, children living in Afar region were 0.4 times less likely to be fully immunized than partially immunized when compared to those living in the Amhara region (Table 2 Panel III).

Contrary to expectation, education of mothers had not shown much difference in the level of full immunization. However, children whose mothers had secondary education were I.7I times more likely to be partially immunized than having had no vaccination when compared to children born to mothers with no education. Children of Muslim mothers had 0.65 times lower chances of being fully immunized than partially immunized when compared to children born to Orthodox Christian mothers (Table 2 Panel III).

Children born to women having frequent access to media were I.87 and I.63 times more likely to be fully immunized than unimmunized and partially immunized respectively when compared to those who had no access to media at all. Statistically significant variation in children's full immunization was observed by maternal health care status during pregnancy. Women who had more than 4 ANC visits were 20 and 8 times more likely to have fully and partially immunized children respectively when compared to those who had not made any visit; and 2.5 times more likely to fully immunize their children than getting them partially immunized. Mothers who made up to 4 ANC visits had 7 and 3 times more likely of getting their children fully and partially immunized respectively than not at all. They were also 2.2 times more likely to fully immunize their children than having them an incomplete immunization when compared to those who had no ANC visit. 
Table 2: Multinomial logistic regression results of the likelihood of partial and full immunization of children age I 2-23 months in Ethiopia, 20I I

\begin{tabular}{|c|c|c|c|c|}
\hline \multirow{2}{*}{ Variables } & \multirow{2}{*}{ Classifications } & $\begin{array}{l}\text { Partially vs. } \\
\text { Unvaccinated }\end{array}$ & $\begin{array}{c}\text { Fully vs. } \\
\text { Unvaccinated }\end{array}$ & $\begin{array}{l}\text { Fully vs. Partially } \\
\text { vaccinated }\end{array}$ \\
\hline & & 1 & II & III \\
\hline \multirow{11}{*}{ Region of residence } & Tigray & $2.63 \quad(.66)$ & $8.38 * *(.67)$ & $3.18 * * *(.25)$ \\
\hline & Afar & $0.05 * * *(.43)$ & $0.02 * * *(.59)$ & $0.40 * \quad(.46)$ \\
\hline & Amhara (ref) & & & \\
\hline & Oromia & $0.24 * * *(.39)$ & $0.17 * * *(.45)$ & $0.70 \quad(.29)$ \\
\hline & Somali & $0.13 * * *(.45)$ & $0.16 * * *(.53)$ & $1.24 \quad(.37)$ \\
\hline & BenishangulGumuz & $0.41 * \quad(.43)$ & $0.52 \quad(.48)$ & 1.28 \\
\hline & SNNP & $0.43 \quad(.43)$ & $\begin{array}{ll}0.43 & (.49) \\
\end{array}$ & $(.31)$ \\
\hline & Gambella & $0.36 * \quad(.50)$ & $0.25 * \quad(.58)$ & $0.68 \quad(.37)$ \\
\hline & Harari & $0.38 \quad(.54)$ & $0.44 \quad(.60)$ & $1.18 \quad(.35)$ \\
\hline & Addis Ababa & $0.37 \quad(1.16)$ & $1.71 \quad(1.16)$ & $4.66 * * *(.42)$ \\
\hline & Dire Dawa & $1.33 \quad(.83)$ & $5.39 * \quad(.85)$ & $4.04 * * *(.34)$ \\
\hline \multirow{2}{*}{ Sex of child } & Male (ref) & & & \\
\hline & Female & $1.10(.16)$ & $1.14 \quad(.19)$ & $1.03 \quad(.13)$ \\
\hline \multirow{3}{*}{ Birth order } & First (ref) & & & \\
\hline & $2-4$ & $1.34 \quad(.26)$ & $1.55 \quad(.31)$ & $1.15 \quad(.20)$ \\
\hline & $5+$ & $1.21 \quad(.31)$ & $\begin{array}{ll}.38 & (.38) \\
\end{array}$ & $1.14 \quad(.26)$ \\
\hline \multirow{3}{*}{ Mother'sage group } & 15-24 (ref) & & & \\
\hline & $25-34$ & $\begin{array}{ll}0.88 & (.2 \mathrm{I}) \\
\end{array}$ & $0.93 \quad(.25)$ & $1.05 \quad(.17)$ \\
\hline & $35-49$ & $1.11 \quad(.31)$ & $1.04 \quad(.38)$ & $0.94 \quad(.26)$ \\
\hline \multirow{3}{*}{ Mother's education } & No education (ref) & & & \\
\hline & Primary & $1.58 \quad(.84)$ & $1.69 \quad(.27)$ & $0.99 \quad(.17)$ \\
\hline & Secondary & $1.7 I^{*}(.24)$ & $2.03 \quad(.86)$ & $1.28 \quad(.33)$ \\
\hline \multirow{2}{*}{ Mother's marital status } & Currently not in union (ref) & & & \\
\hline & Currently in union & $0.78 \quad(.37)$ & $0.98 \quad(.44)$ & $1.26 \quad(.29)$ \\
\hline \multirow{4}{*}{ Mother's religion } & Orthodox (ref) & & & \\
\hline & Protestant & $1.50 \quad(.32)$ & $1.05 \quad(.37)$ & $0.70 \quad(.25)$ \\
\hline & Muslim & $2.41 * *(.30)$ & $1.57 \quad(.33)$ & $0.65 *(.21)$ \\
\hline & Others & $\begin{array}{ll}2.27 \quad(.63) \\
\end{array}$ & $\begin{array}{ll}.73 \quad(.76) \\
\end{array}$ & $0.76 \quad(.53)$ \\
\hline \multirow{3}{*}{ Mother's work status } & Not working (ref) & & & \\
\hline & Working in family business & $1.06 \quad(.25)$ & $(.30)$ & $1.06 \quad(.20)$ \\
\hline & Employed & $\begin{array}{ll}.35 & (.20) \\
\end{array}$ & 1.57 & $1.17 \quad(.15)$ \\
\hline \multirow{3}{*}{ Mother's access to media } & Not at all (ref) & & & \\
\hline & Sometimes & $0.90 \quad(.18)$ & $0.86 \quad(.23)$ & $0.96 \quad(.16)$ \\
\hline & Frequently & $1.15 \quad(.25)$ & I.87* (.29) & $1.63 * *(.18)$ \\
\hline \multirow{3}{*}{ ANC visit } & No ANC (ref) & & & \\
\hline & Up to 4 times & $3.15 * * *(.22)$ & $6.98 * *(.25)$ & $2.22 * * *(.15)$ \\
\hline & More than 4 times & $8.09 * *(.62)$ & $20.18 * * *(.64)$ & $2.49 * * * *(22)$ \\
\hline \multirow{2}{*}{ Place of delivery } & Home (ref) & & & \\
\hline & Health facility & $0.99 \quad(.34)$ & $1.16 \quad(.38)$ & $1.17 \quad(.21)$ \\
\hline \multirow{3}{*}{ Father's education } & No Education ( $r$ ff) & & & \\
\hline & Primary & $(.19)$ & 1.03 & $0.86(.16)$ \\
\hline & Secondary and above & $(.40)$ & $1.23 \quad(.45)$ & $0.75 \quad(.27)$ \\
\hline \multirow[t]{2}{*}{ Father's occupation } & Non-agricultural (ref) & & & \\
\hline & Agricultural & $0.82 \quad(.23)$ & 0.79 & $0.96(.18)$ \\
\hline \multirow[t]{3}{*}{ Household wealth status } & Poor (ref) & & & \\
\hline & Medium & $(.19)$ & $1.37 \quad(.23)$ & $1.34 \quad(.16)$ \\
\hline & Rich & $1.24 \quad(.21)$ & $2.14 * *(.25)$ & $1.72 * *(.17)$ \\
\hline \multicolumn{2}{|c|}{ Number of cases included in the analysis } & 1649 & 1649 & 1649 \\
\hline
\end{tabular}

*** $p<0.001 \quad *^{*} p<0.01 \quad * p<0.05 \quad$ ref - reference category

Figures in parentheses are standard error.

Source: Computed by authors from the 20I I EDHS data

Children from rich households were 2.14 and 1.72 times more likely to be fully immunized than being unimmunized and partially immunized respectively when compared to those living in poor households.
On the other hand, no statistically significant difference in immunization status was observed by sex and birth order of children, age group, current marital status and work status of mothers, place of 
delivery, and educational level and occupational status of fathers (Table 2 Panels I-III).

Separate model was fitted for rural-urban differentials in child immunization as Addis Ababa City Administration (having an equivalent status of regional administration) does not have a rural setting. The result showed that children living in Addis Ababa and other urban areas were respectively 4.24 and I.6I times more likely to be fully than partially immunized compared to those in rural areas. However, there was no statistically significant difference between rural and urban areas in receiving full or partial immunization as compared to not receiving any vaccination when all independent variables except region were controlled (result not shown here).

\section{Discussion}

Ethiopia is committed to achieving full immunization coverage via developing health related policies and strategies, construction of health posts, training and deployment of health extension workers, and expending huge amount of financial resources. Despite improvements in access to health services and awareness of the community, much is remaining to meet the target. The results of this study show that variation in the coverage of full immunization is associated with regional differences, access to mass media, antenatal care visit, and household wealth status.

\section{Geographical variation in full immunization reflects differences in access to vaccination services and implementation of the routine immunization program:}

Previous studies in the country documented supply side factors as an obstacle to child immunization program (Kidane and Tekie 2003; Kidane et al. 2008). These factors include disparity in the availability of health posts, supply of vaccines and other equipment, deployment of health extension workers/human resources, and utilization of community based organizations. Variation in the availability of health posts explains regional disparity in children's access to immunization services. Data from the planning department of Afar Region's Health Bureau shows that 24 of the 338 rural kebeles in Afar region do not have health posts. Even in areas where health posts are constructed, mobility between rural villages requires longer time. An informant from health bureau of Afar region mentioned that although the Ministry of Health recommends the provision of health services at health posts in $5 \mathrm{~km}$ radius, the average is about $13 \mathrm{~km}$ in the region. The outreach services of the health extension program tends to be affected by transportation problem as most of the service providers need to travel on foot for longer distance in a geographically diverse settings (i.e. hilly mountains, rugged terrains, and gorgeous valleys) of rural Ethiopia. Some of the HEWs interviewed in Amhara and Oromia regions indicate that it took them about two and half hours to reach the remotest village. In regions that are predominantly pastoral (e.g. Afar and Somali), there is also weather-induced seasonal movement of the communities where HEWs could not move with them to provide health services including child immunization.

All health posts are not equally equipped with the required facilities (Medhanyie et al. 20I2). For instance, among the sample of 293 health posts covered in the survey conducted by the Centre for National Health Development in Ethiopia (20II), only less than a quarter (24\%) were equipped with all the necessary minimum set of medical equipment required for provision of static and outreach immunization services. Regular medical supply is further challenged by transportation problem as there are health posts that are not connected via allweather road. Some of the HEWs interviewed in Afar and Amhara regions mentioned that they collect the vaccines from the woreda health centre, which is often found at a distant location from the health post or their place of residence, on out-reach immunization service days due to lack of refrigerator and/or electricity.

The distribution of health personnel is not equal in all regions. Ministry of Health recommends two HEWs at one health post. However, there are health posts that have either only one HEW or none at all. In Afar region, for example, though $676 \mathrm{HEWs}$ were expected to serve in the 338 rural kebeles, there were only 59I HEWs by June 20I4. Health services in some of the regions are also affected by lack of well qualified staff (Ministry of Health 20II). In a study conducted by the Centre for National Health Development (20II), more than three-fourth of the HEWs feel that their duties and responsibilities require more training than the training they have received. According to informants from Afar Region Health Bureau, the previous trainings were given to males who had completed at least grade 4 due to lack of eligible candidates (i.e. females who had completed grade 10). Some of the HEWs interviewed in Amhara, Oromia, and Afar regions also reported to have inadequate skill of giving vaccines.

Among regions that are dominantly rural, only Tigray has managed to provide full vaccination to about $60 \%$ of the children under age one. Data obtained from the regional health bureau shows that there are two HEWs in all health posts. 
Implementation of routine immunization program in the region is strongly monitored through Woreda net communication system and health management information system. The relatively better success of full immunization in Tigray could also be attributed to the well-functioning of the community based organizations in health promotion activities and community mobilization for immunization and tracing of defaulters (Kidane and Tekie 2003). According to an informant from Tigray Region Health Bureau, there were 29,000 development groups with 25 to 30 members that played decisive roles in increasing the awareness of the community to improve health service utilization including child immunization. In Dire Dawa and Addis Ababa, where level of awareness on children's immunization is believed to be better, most of the children are fully immunized. Despite the relatively permanent settlement pattern of its population and comparable socio-economic development, the level of full immunization is very low in Oromia region, which requires further investigation.

Frequent access to media plays substantial roles in enhancing children's full immunization:

Similar to the findings in Bangladesh (Afzal and Zainab 20I2) and Uganda (Bbaale 20I3), children's full immunization is higher among mothers who have frequent access to mass media. Children's full immunization requires not only availability of services in the residential area but also the commitment of parents to get a child all the required number of vaccines. Hence, improving active participation of a community plays a key role in creating awareness of and public demand for the benefits of immunization (WHO et al. 2009). Access to media is one of the means through which health seeking behaviour of the community can be enhanced. In Ethiopia, lack of awareness on the importance of immunization, fear of side effects, lack of information on the time of vaccination, and wrong perception about contraindication are mentioned as major reasons for failure to fully immunize children (Kidane and Tekie 2003; Mohammed and Atomsa 20I3). These problems are expected to be minimal among women with frequent access to media as they are more likely to be alert about the relevance of vaccination to protect children against illness and may consider immunization as one of the best ways of ensuring their survival.

\section{ANC visit accelerates child immunization:}

Consistent with previous empirical evidence in Ethiopia (Etana and Deressa 2012) and elsewhere (Rahman and Obaida-Nasrin 20I0), full immunization of children is associated with mothers' visit of health facilities for ANC. The higher chance of full immunization among children born to women who utilize ANC services is mainly related to more acquaintance with the health facility as well as understanding of the significance of immunization in protecting a child against illness. It could also be linked to the regular maternal and child health related education and counselling provided at the health facilities. All the interviewed HEWs indicated that child immunization is one of the components of health education given during ANC visits. Moreover, observing the vaccination services of children during the visits is believed to encourage mothers to do the same for their children. The direct relationship between ANC visit and child immunization has implications for the breaking-off of socio-cultural barriers in seeking modern health services. A mother who visits a clinic during her pregnancy is supposed to feel free to regularly take her child to clinic for immunization than others who do not. In tradition bounded society like Ethiopia, breaking customary norms and values and seeking vaccination for a newly born child requires strong determination and decision making autonomy on the part of a mother as there would be some resistances from partners and other community members. It is thus an encouraging result that paying due emphasis to ANC and making the services available is tantamount to enhancing the survival chance of a child through maximizing the likelihood of receiving full immunization.

\section{Household's economic status significantly predicts} full immunization of children in Ethiopia:

Resembling previous findings (Tadesse et al. 2009; Ghei et al. 2010; Payne et al. 2013), Ethiopian children born to economically better-off households have better immunization coverage than others. Income operates through direct and indirect ways to determine health (Wagstaff et al. 2004). In Ethiopia, as vaccination services are given free of charge, there is no direct cost of child vaccination. Hence, the significance of socio-economic status in predicting children's full immunization is associated with the indirect cost of visiting health posts. This includes payment for transportation to and from the health facility and other costs during the visit for immunization. Poor households may miss child vaccination schedule if they could not afford to pay for transportation or run short of money to cover any of the expenses required whilst going to the clinic. For poor parents, the opportunity cost of regularly taking children to health facilities is high (Canavati et al. 20I I) due to which children are left either partially immunized or not immunized at all. Given the responsibilities of HEWs to implement all the packages of the health extension program and 
transportation problem in most parts of rural areas, a child may not be regularly visited at its residence. In the absence of well-implemented out-reach services, competing demand for family members' time likely results in failure to properly utilize immunization services (Kidane and Tekie 2003; Banteyerga 20 I I).

\section{Conclusion}

Ethiopia is a country striving for all-round transformation of its socio-economic and demographic structures. The prospect for future development of the country is mainly the function of quality of children. This is dependent on the current investment of government and parents in children. Ensuring children's full immunization is not only a human right issue but also the responsibility of building the future through cultivation of healthy and productive children. Full immunization is a promising mechanism of reducing morbidity, mortality, and disability of children. Hence, substantial regional gap in immunization coverage requires concerted efforts of government structures at different levels in reaching the children who are not benefiting from EPI due to various household and institutional constraints.

Even though the Ethiopian policy guideline on EPI states that HEWs should give immunization services and trace defaulters to maximize full immunization coverage, it practically seems that more human, material and financial resources shall be made available to achieve the target. As the vaccine to prevent the diseases through routine immunization shall be given to each and every infant on time, the task needs to be administered and supported by a group with adequate knowledge and skill, as well as less work burden. Ethiopia is a country with diverse physical setting, cultural context, and distribution of health facilities. Hence, the attempts to reach all children shall consider this diversity by designing flexible intervention strategies and strong monitoring of its implementations.

The lower likelihood of full immunization among children from poor families calls for addressing their economic constraints and designing convenient measures to ensure that the children are fully protected from vaccine preventable diseases. Significantly improving utilization of ANC services not only contribute to reduction of infant and maternal mortality but also substantially improve full immunization coverage. The content and timing of media intervention about the benefits and schedules of immunization shall be sustained being sensitive to the socio-cultural settings of the country for effective communication and mobilization of the community for proper utilization of immunization services. These would enhance achieving the target of full immunization of all children thereby making a good foundation to build the future through proper investment in the health of children.

\section{Acknowledgements}

We would like to thank the Central Statistical Agency of Ethiopia and ICF International for allowing us to use the 201I Ethiopian Demographic and Health Survey Data set on which this study is mainly based. We are also very much grateful to the anonymous reviewers for their insightful comments.

\section{References}

Afzal, N. and Zainab, B. 20I2. "Determinants and Status of Vaccination in Bangladesh" Dhaka University Journal of Science 60, (I): 47-5I.

Babirye, J. N., Rutebemberwa, E., Kiguli, J., Wamani, H., Nuwaha, F. and Engebretsen, I. M. $201 \mathrm{I}$. "More Support for Mothers: A Qualitative Study on Factors Affecting Immunisation Behaviour in Kampala, Uganda" BMC Public Health II, 723

Banteyerga, H. 20II. "Ethiopia's Health Extension Program: Improving Health through Community Involvement" MEDICC Review I3, (3): 46-49.

Bbaale, E. 2013. "Factors Influencing Childhood Immunization in Uganda" Journal of Health Population and Nutrition 31, (I): I I8-I29.

Bishai, D., Suzuki, E., Mcquestion, M., Chakraborty, J. and Koenig, M. 2002. "The Role of Public Health Programmes in Reducing Socioeconomic Inequities in Childhood Immunization Coverage" Health Policy and Planning 17, (4): 4I 2-4I9.

Bronte-Tinkew, J. and Dejong, G. F. 2005. "Do Household Structure and Household Economic Resources Predict Childhood Immunization? Evidence from Jamaica and Trinidad and Tobago" Population Research and Policy Review 24, (I): 27-57.

Canavati, S., Plugge, E., Suwanjatupporn, S., Sombatrungiaroen, S. and Nosten, F. 20II. "Barriers to Immunization among Children of Migrant Workers from Myanmar Living in Tak Province, Thailand" Bulletin of the World Health Organization 89, 528-531.

Centre for National Health Development in Ethiopia, Columbia University 201I. Ethiopia Health Extension Program Evaluation Study, 2007-2010, Volume-II.Health post and HEWs performance survey.Addis Ababa, Ethiopia: Centre for National Health Development in Ethiopia, Columbia University.

Central Statistical Agency [Ethiopia] and ICF International 2012.Ethiopia Demographic and Health Survey 20II. Addis Ababa, Ethiopia and 
Calverton, Maryland, USA: Central Statistical Agency and ICF International.

Dixit, P., Dwivedi, L. K. and Ram, F. 2013. "Strategies to Improve Child Immunization via Antenatal Care Visits in India: A Propensity Score Matching Analysis" PLOS ONE 8, (6): I-I0.

Etana, B. and Deressa, W. 2012. "Factors Associated with Complete Immunization Coverage in Children Aged 12-23 Months in Ambo Woreda, Central Ethiopia” BMC Public Health I2, 566.

Fadeyi, A. O. 2013. "Mothers' Health Seeking Behaviour and Childhood Immunization in Lagos and Ogun States" International Journal of Social Sciences and Humanities Reviews 4, (2): 13 - 26.

Fadnes, L. T., Jackson, D., Engebretsen, I. M., Zembe, W., Sanders, D., Sommerfelt, H. and Tylleskär, T. 201I."Vaccination Coverage and Timeliness in Three South African Areas: A Prospective Study" BMC Public Health II 404.

Gage A. J., Sommerfelt, A. E. and Piani, A. L. 1997. "Household Structure and Childhood Immunization in Niger and Nigeria" Demography 34, 295-309.

Ghei, K., Agarwal, S., Subramanyam, M. A. and Subramanian, S. V. 2010. "Association between Child Immunization and Availability of Health Infrastructure in Slums in India" Archives of Paediatrics \& Adolescent Medicine 164, (3): 243249.

Kidane, T. and Tekie, M. 2003. "Factors Influencing Child Immunization Coverage in a Rural District of Ethiopia, 2000" Ethiopian Journal of Health Development 17, (2): 105-II0.

Kidane, T., Yigzaw, A., Sahilemariam, Y., Bulto, T., Mengistu, H., Belay, T., Bisrat, F., Benti, D., Mbakuliyemo, N. and Olusegun, B. 2008. "National EPI Coverage Survey Report in Ethiopia, 2006" Ethiopian Journal of Health Development 22, (2): I48-I57.

Medhanyie, A., Spigt, M., Kifle, Y., Schaay, N., Sanders, D., Blanco, R., GeertJan, D. and Berhane, Y. 2012. "The Role of Health Extension Workers in Improving Utilization of Maternal Health Services in Rural Areas in Ethiopia: A Cross Sectional Study" BMC Health Services Research 12, 352.

Ministry of Health [Ethiopia] 20I I.Policy Guidelines on the National Expanded Programmeon Immunization in Ethiopia. Addis Ababa, Ethiopia.

Ministry of Health [Ethiopia] 2010a. Ethiopia: National Expanded Programme on Immunization Comprehensive Multi-Year Plan 201I - 2015. Addis Ababa, Ethiopia

Ministry of Health [Ethiopia] 2010b. Health Sector Development Program IV - 2010/II-I0I4/I5. Addis Ababa, Ethiopia
Mohammed, H. and Atomsa, A. 2013. "Assessment of Child Immunization Coverage and Associated Factors in Oromia Regional State, Eastern Ethiopia" Science, Technology, and Arts Research Journal 2, (I): 36-4I.

Mukungwa, T. 2015. "Factors Associated with Full Immunization Coverage amongst Children aged 12 -23 Months in Zimbabwe" African Population Studies 29, (2): |76|-|774.

Munshi, R. and Lee, S. 2000. Child immunization in Madhya Pradesh.National Family Health Survey Subject Reports, Number 15. International Institute for Population Sciences, Mumbai, India and East-West Center, Population and Health Studies, Hawaii, U.S.A.

Odusanya, O. O., Alufohai, E. F., Meurice, F. P. and Ahonkhai, V. I. 2008."Determinants of Vaccination Coverage in Rural Nigeria" BMC Public Health 8, $38 \mathrm{I}$.

Pande, R. and Yazbeck, A. 2002.Beyond national averages for immunization in India: income, gender, and regional inequalities. World Bank, Washington, DC.

Payne, S., Townend, J., Jasseh, M., Jallow, Y. L. and Kampmann, B. 2013."Achieving Comprehensive Childhood Immunization: An Analysis of Obstacles and Opportunities in The Gambia" Health Policy and Planning 2013; II I.Doi: 10.1093/heapol/czt004

Rahman, M. and Obaida-Nasrin, S. 2010. "Factors Affecting Acceptance of Complete Immunization Coverage of Children under Five Years in Rural Bangladesh" SaludPública de México 52, (2): I34140.

Rutherford, M. E., Dockerty, J. D., Jasseh, M., Howie, S. R., Herbison, P., Jeffries, D. J., Mulholland, K., Adegbola, R. A. and Hill, P. C. 2009. "Preventive Measures in Infancy to Reduce Under-five Mortality: A Case-control Study in The Gambia" Tropical Medicine and International Health 14, (2): 149-155.

Tadesse, H., Deribew, A. and Woldie, M. 2009. "Predictors of Defaulting from Completion of Child Immunization in South Ethiopia, May 2008 A Case Control Study" BMC Public Health 9, I50.

UNICEF 20I3. Immunization: facts and figures. April, 20I3. New York, USA.

UNICEF and WHO 20I2. Immunization summary: A statistical reference containing data through 20II. New York, USA and Geneva, Switzerland.

Wagstaff, A., Bustreo, F., Bryce, J., Claeson, M. and the WHO-World Bank Child Health and Poverty Working Group 2004. "Child Health: Reaching the Poor" American Journal of Public Health 94, (5): 726-736. 
Waters, H. R., Dougherty, L., Tegang, S., Tran, N., Wiysonge, C. S., Long, K., Wolfe, N. D. and Burke, D. S. 2004."Coverage and Costs of Childhood Immunizations in Cameroon" Bulletin of the World Health Organization 82, 668-675.

WHO 2010. WHO vaccine preventable diseases: Monitoring system, 2010 global summary. Geneva: World Health Organization.

WHO 2002. WHO antenatal care randomized trail: Manual for the implementation of the new model. Geneva: World Health Organization.

WHO and UNICEF 20I3. Global immunization data, July 20I3.Geneva, Switzerlandand New York, USA.

WHO, UNICEF and the World Bank 2009.State of the world's vaccines and immunization. $3^{\text {rd }}$ ed. Geneva: World Health Organization.

Rapport descriptif, Ouagadougou, ISSP/Université de Ouagadougou, $7 \mathrm{l}$ p.
Timaeus I. M., L. Lush, (1995), "Intra-urban Differentials in Child Health," Health Transition Review 5(2): 163-90.

Timsit, JF, C. Alberti, S. Chevret (2005), “ Le modèle de Cox," Revue des Maladies Respiratoires, 22(7) : $7 \mathrm{p}$.

UNITED NATIONS (2015), General assembly, sixtyninth session, 12 August 2015 http://www.undp.org/content/undp/fr/home/mdg overview/post-20I5-development-agenda.html (site visited on December 12, 20I5).

UNITED NATIONS HUMAN SETTLEMENT PROGRAMME (UN-HABITAT) (2013), State of the world's cities 20/2/20/3, New York, Routledge, $185 \mathrm{p}$.

WHO. Geneva: World Health Organization; (20I2). Verbal autopsy standards: the $2012 \mathrm{WHO}$ verbal autopsy instrument. 